\title{
Low-dose taurine upregulates taurine transporter expression in acute myocardial ischemia
}

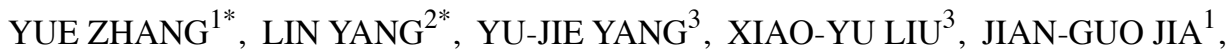

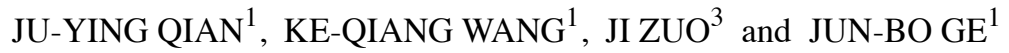 \\ ${ }^{1}$ Department of Cardiology, Zhongshan Hospital, Fudan University, Shanghai Institute of Cardiovascular Diseases; \\ ${ }^{2}$ Eye and ENT Hospital, Fudan University; ${ }^{3}$ Department of Cellular and Genetic Medicine, \\ Shanghai Medical College, Fudan University, Shanghai, P.R. China
}

Received November 6, 2012; Accepted January 9, 2013

DOI: $10.3892 / \mathrm{ijmm} .2013 .1264$

\begin{abstract}
Taurine exerts a protective effect on cardiomyocytes. The aim of this study was to determine whether the protective effect of taurine is associated with the upregulation of taurine transporter (TAUT) expression in acute myocardial ischemia (AMI). To this end, we investigated TAUT expression in cultured cardiomyocytes exposed to hypoxia as well as in rats with AMI treated with or not with taurine. The morphology of cardiac tissues, the apoptosis of cardiomyocytes and cardiac function were examined. In addition, the taurine content and the expression of TAUT were measured. Our data demonstrated that taurine reversed the apoptosis induced by hypoxia and AMI, thereby, effectively protecting the myocardium. Taurine content and TAUT expression levels were significantly decreased when cardiomyocytes and cardiac tissues were subjected to hypoxic or ischemic stress, while the expression of cysteine sulfinate decarboxylase was unchanged. Moreover, treatment with taurine (100 mg/kg/day) significantly upregulated TAUT expression and elevated the taurine content in ischemic myocardial tissues. In vitro, the low-dose $(40 \mathrm{mM})$ but not the high-dose $(120 \mathrm{mM})$ administration of taurine significantly induced TAUT expression and elevated the intracellular taurine content in hypoxic cardiomyocytes. In conclusion, our data demonstrate that taurine exerts a protective effect on the ischemic myocardium. Low-dose but not high-dose taurine treatment upregulated TAUT expression and increased the intracellular taurine content in cardiomyocytes subjected to hypoxia as well as in AMI tissues.
\end{abstract}

Correspondence to: Professor Jun-Bo Ge, Department of Cardiology, Zhongshan Hospital, Fudan University, Shanghai Institute of Cardiovascular Diseases, 136 Yi Xue Yuan Road, Shanghai 200032, P.R. China E-mail: ge.junbo@zs-hospital.sh.cn

Professor Ji Zuo, Department of Cellular and Genetic Medicine, Shanghai Medical College, Fudan University, 130 Donganroad, Shanghai 200032, P.R. China

E-mail: jzuo@shmu.edu.cn

${ }^{*}$ Contributed equally

Key words: taurine, taurine transporter, acute myocardial ischemia, hypoxia

\section{Introduction}

Taurine, a $\beta$-aminosulfonic acid, is the most abundant free amino acid in excitable mammalian tissues, with intracellular concentrations of $20-70 \mathrm{mmol} / \mathrm{kg}$ in the heart $(1,2)$. Accumulating evidence indicates that taurine may play a cytoprotective role in the heart. Indeed, the oral supplementation of taurine has been shown to be effective in animal models and human patients with congestive heart failure and cardiomyopathy (3-6). The main mechanisms behind the cytoprotective effects of taurine include the maintenance of calcium $\left(\mathrm{Ca}^{2+}\right)$ homeostasis, the regulation of osmotic balance and antioxidant and anti-apoptotic activity (6-10). Physiologically, high intracellular taurine levels are maintained by the combination of membrane taurine transporter (TAUT) activity and endogenous biosynthesis. Since the capacity to synthesize taurine in most tissues is limited (including the heart), maintenance of the large intracellular taurine pool mainly depends upon the activity of TAUT $(11,12)$.

Inducing arrhythmias and even heart failure, acute myocardial ischemia (AMI) is one of the most serious cardiovascular events. In this setting, the supplementation of exogenous taurine has been demonstrated to produce preventive and therapeutic effects on AMI $(13,14)$. However, it seems unlikely that taurine treatment is simply a replacement therapy. Therefore, in this study, we investigated changes in taurine content and TAUT expression in hypoxic cardiomyocytes and ischemic myocardial tissues treated or not with taurine.

\section{Materials and methods}

Animals, cell lines, protocol and procedure. Experimental procedures were performed using pathogen-free, adult male Sprague-Dawley (SD) rats, weighing 250-300 g (Shanghai Institute of Materia Medica, Chinese Academy of Sciences, Shanghai, China). The experimental protocol was approved by the Shanghai Medical Experimental Animal Care and Use Committee. SD rats were anesthetized by intraperitoneal injections of ketamine $(100 \mathrm{mg} / \mathrm{kg})$. The rats were placed in a supine position after being shaved on the chest and then intubated with positive-pressure ventilation $(180 \mathrm{ml} / \mathrm{min})$ with room air using a SAR-830/A Small Animal Ventilator 
(CWE, Inc., Weston, WI, USA). Under sterile conditions, the heart was exposed via a left thoracotomy at the level of the 5 th intercostal space. AMI was created by left coronary artery ligation $2 \mathrm{~mm}$ below the left atrium with a 6-0 prolene suture. Regional myocardial ischemia was confirmed through the observation of a rapid discoloration over the anterior surface of the left ventrical together with the development of akinesia and dilatation over the area at risk. The sham-operated control rats only received thoracotomy without left coronary artery ligation. All rats received an intraperitoneal injection of $1 \mathrm{ml}$ physiological saline or $100 \mathrm{mg} / \mathrm{kg} /$ day of taurine (Sigma) for 3 consecutive days before modeling. The rats were assigned into 4 groups ( $\mathrm{n}=18 /$ group): i) control group (untreated sham-operated group); ii) taurine-treated control group (shamoperated control group treated with taurine); iii) AMI group; and iv) taurine-treated AMI group. In each group, 6 animals were euthanized 30 min after modeling, 6 were euthanized $2 \mathrm{~h}$ after modeling, and 6 were euthanized 2 weeks after modeling at the completion of an echocardiogram examination.

H9C2 cells were purchased from the Shanghai Institute of Cell Biology, Chinese Academy of Sciences, Shanghai, China. The $\mathrm{H} 9 \mathrm{C} 2$ cells were maintained at $37^{\circ} \mathrm{C}$ with $5 \%$ carbon dioxide $\left(\mathrm{CO}_{2}\right)$ in air atmosphere in Dulbecco's modified Eagle's medium (DMEM) supplemented with 10\% (volume/volume) heat-inactivated fetal bovine serum and antibiotics $(100 \mathrm{U} / \mathrm{ml}$ penicillin and $100 \mathrm{mg} / \mathrm{ml}$ streptomycin). For hypoxic conditions, the $\mathrm{H} 9 \mathrm{C} 2$ cells were cultured at $37^{\circ} \mathrm{C}$ with $1 \%$ oxygen and $5 \% \mathrm{CO}_{2}$ in a hypoxic incubator (Ruskinn Invivo2 200; Ruskinn Technology). In the taurine treatment groups various doses of taurine were added to the DMEM $24 \mathrm{~h}$ prior to the induction of hypoxia. To measure the taurine content in the cardiomyocytes, the medium was removed and replaced with standard incubation buffer [mmol/l: KCl 3, NaCl 125, $\mathrm{KH}_{2} \mathrm{PO}_{4}$ $12, \mathrm{MgSO}_{4} 1.2, \mathrm{CaCl}_{2} 1.3, \mathrm{NaHCO}_{3}$ 5, HEPES 20, $\mathrm{pH} 7.4$, and $0.2 \%$ bovine serum albumin (BSA)].

Measurement of taurine content by high-performance liquid chromatography (HPLC). Taurine content in the hypoxic cardiomyocytes and myocardial tissues and the plasma of AMI rats was measured by reversed-phase HPLC. In addition, the plasma of 10 AMI patients and 10 healthy volunteers along with their clinical data were collected and taurine content in the plasma was also measured by HPLC. The study was approved by the Zhongshan Hospital Research Ethics Committee and the informed consent was obtained from each patient according to the committee's regulations. Approximately $1 \times 10^{6}$ hypoxic cardiomyocytes or $0.1 \mathrm{~g}$ ischemic cardiac tissue were homogenized with normal saline. The homogenates were centrifuged at $14,000 \mathrm{rpm}$ for $15 \mathrm{~min}$ at $4^{\circ} \mathrm{C}$. The supernatants or the plasma were mixed with $0.2 \mathrm{M}$ perchloric acid and centrifuged at $12,000 \mathrm{rpm}$ for $15 \mathrm{~min}$ at $4^{\circ} \mathrm{C}$.

HPLC was performed according to a previous study (15). Briefly, the supernatants were purified in a dual-bed ionexchange column (2.5 cm of AG 1-X8 100-200 mesh in the chloride form; $>2.5 \mathrm{~cm}$ of AG 50W-X8 200-400 mesh in the hydrogen form), eluted with $2 \mathrm{ml}$ ultrapure water, and then lyophilized. The sample or standard were dissolved in $100 \mu \mathrm{l}$ of water prior to HPLC analysis on a Waters system (Waters Corp., Milford, MA, USA) equipped with a $3.9 \times 150 \mathrm{~mm}$ Nova-Pak $\mathrm{C}_{18}$ column and a model 470 scanning fluorescence detector. Isocratic elution was performed at a flow rate of $2 \mathrm{ml} / \mathrm{min}$ using $43 \%$ solvent A $\left(0.05 \mathrm{~mol} / 1 \mathrm{NaH}_{2} \mathrm{PO}_{4}, \mathrm{pH} 5.3\right.$, plus $5 \mathrm{~mol} / \mathrm{l} \mathrm{NaOH})$ mixed with $57 \%$ solvent $\mathrm{B}(0.05 \mathrm{~mol} / \mathrm{l}$ $\mathrm{NaH}_{2} \mathrm{PO}_{4}$ in $75 \%$ methanol-water). Glutamine, added after ion exchange chromatography, was used as the internal standard. The standard curve was linear for the taurine content in the sample concentration, and the recovery of taurine was $>90 \%$. The value of taurine was expressed as $\mathrm{nmol} / \mathrm{mg}$ of protein in cardiomyocytes, $\mu \mathrm{mol} / \mathrm{g}$ in cardiac tissues, and $\mu \mathrm{mol} / 1$ in plasma.

Quantitative real-time PCR analysis. Total ribonucleic acid (RNA) was extracted from the cells and frozen ischemic areas of the cardiac tissue specimens ( $\mathrm{n}=6 /$ group) using TRIzol reagent (Invitrogen). Total RNA ( $2 \mu \mathrm{g}$ ) was reverse transcribed using a PrimeScript RT reagent kit (Takara). Reverse transcriptionpolymerase chain reaction (PCR) was performed before quantitative real-time PCR. Messenger RNA expression was determined by real-time PCR using SYBR Premix Ex Taq II (Takara). PCR amplification cycles were programmed for $30 \mathrm{sec}$ at $95^{\circ} \mathrm{C}$, followed by $40 \mathrm{cycles}$ of $95^{\circ} \mathrm{C}$ for $30 \mathrm{sec}, 60^{\circ} \mathrm{C}$ for $30 \mathrm{sec}$ and $72^{\circ} \mathrm{C}$ for $40 \mathrm{sec}$. Data were collected after each annealing step, and $\alpha$-tubulin was used as the endogenous control. mRNA expression was calculated using the $2^{-\Delta \Delta \mathrm{Ct}}$ method. The primers used for the amplification of rat genes were as follows: TAUT forward, 5'-CAACTTCACTTCGCCTG TGA-3' and reverse, 5'-CTTGCTCTTGTGCCATGAAG-3'; cysteine sulfinate decarboxylase (CSD) forward, 5'-TGATCCC TGAGGATCTGGAG-3' and reverse, 5'-ACTCAAATCCTT CCCGCTTT-3'; and $\alpha$-tubulin forward, 5'-CACCCGTCTT CAGGGCTTCTTGGTTT-3' and reverse, 5'-CATTTCACCAT CTGGTTGGCTGGCTC-3'.

Western blot analysis. Protein was extracted from the cells and the ischemic areas of cardiac tissues. The protein concentration was determined using the BCA protein assay (Pierce). Equal amounts of protein were subjected to $12 \%$ sodium dodecyl sulfate-polyacrylamide gel electrophoresis (SDS-PAGE). Following gel electrophoresis, the proteins were transferred onto polyvinylidene difluoride (PVDF) membranes (Immobilon-P; Millipore). The membranes were blocked for $1 \mathrm{~h}$ at room temperature in 5\% non-fat dry milk in Tris-buffered saline (TBS) containing $0.05 \%$ Tween-20. Following overnight incubation at $4^{\circ} \mathrm{C}$ with primary antibodies, the membranes were incubated with horseradish peroxidase-labeled secondary antibody (Chemicon) for $1 \mathrm{~h}$ at room temperature. Peroxidase activity was detected by chemiluminescence (SuperSignal West Femto Luminol Substrate and Peroxide Buffer; Pierce). The primary antibodies used included anti-TAUT (1:100; Santa Cruz Biotechnology, Inc.), anti-Bax (1:1,000; Epitomics), antiBcl-2 (1:1,000; Cell Signaling Technology) and anti-tubulin (1:200; Beyotime Technology) antibodies.

Immunofluorescence and immunohistochemical staining for TAUT. Cardiomyocytes were stained by immunofluorescence and the ischemic areas of the cardiac tissue sections were stained by immunohistochemistry to assess the distribution of TAUT, as described below. First, the cultured cells were grown on slides and then washed and fixed. Cells were then incubated with primary antibody against TAUT (1:50; Santa Cruz 

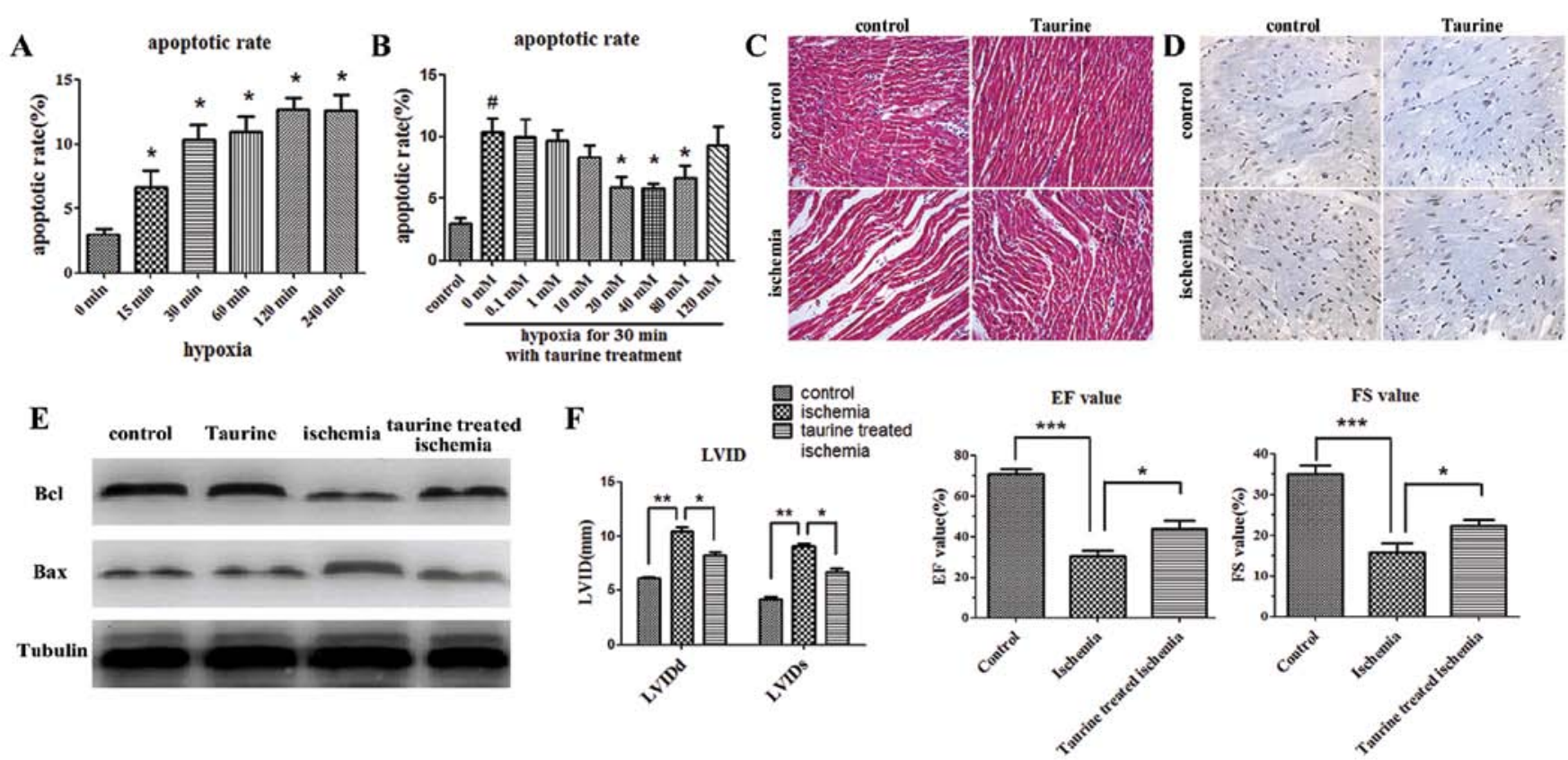

Figure 1. Taurine treatment reverses the apoptosis of cardiomyocytes induced by hypoxia and acute myocardial ischemia and protects the cardiomyocytes. (A and B) The apoptotic rates of the cardiomyocytes measured by Annexin V and PI assays. (C and D) Hematoxylin and eosin and TUNEL staining of ischemic cardiac tissues in the 4 groups (original magnification, x200). (E) Protein levels of Bcl-2 and Bax in cardiac tissues measured by western blot analysis. (F) Left ventricular diastolic and systolic internal dimensions (LVIDd and LVIDs, respectively), percentage of fractional shortening (FS) and ejection fraction (EF) values measured by an echocardiogram. Columns represent the means of 6 samples in each group; bars represent the means \pm SEM; ${ }^{*} \mathrm{P}<0.05$; ${ }^{* *} \mathrm{P}<0.01 ;{ }^{* * *} \mathrm{P}<0.001$.

Biotechnology, Inc.) and rabbit anti-goat tetramethyl rhodamine isothiocyanate-conjugated secondary antibody (1:200; Invitrogen) before staining with 4',6-diamidino-2-phenylindole (DAPI). The fluorescent images were visualized under a confocal microscope (FV-1000; Olympus). The ischemic areas of the cardiac tissue sections were incubated with primary antibody against TAUT (1:50; Santa Cruz Biotechnology, Inc.), and donkey anti-goat IgG/horseradish peroxidase (1:100; Serotec) was applied as the secondary antibody. For the negative controls, primary antibodies were replaced by phosphate-buffered saline (PBS). Staining was evaluated by 2 independent observers.

Hematoxylin and eosin $(H \& E)$ and TUNEL staining. The formalin-fixed and paraffin-embedded tissues were cut into sections ( $4 \mu \mathrm{m}$ thick) for histological studies using H\&E and terminal deoxynucleotidyl transferase-mediated deoxyuridine triphosphate nick end-abeling (TUNEL) staining. TUNEL staining was performed using a TUNEL kit (No. 11684817910, Roche) according to the manufacturer's instructions. At least 5 random fields from each section were counted in order to quantify the histological images.

Annexin V and propidium iodide (PI) assays. The $\mathrm{H} 9 \mathrm{C} 2$ cells were cultured in DMEM in 6-well plates to produce colonies at $80-90 \%$ confluence. Various doses of taurine were added to the culture solution, and the cells were incubated for $24 \mathrm{~h}$ prior to the induction of hypoxia. In order to detect early apoptotic activity, an Annexin V-FITC/PI Apoptosis Detection kit (KeyGen) was used according to the manufacturer's instructions. $\mathrm{H} 9 \mathrm{C} 2$ cells were washed with cold PBS and added to $200 \mu 1$ of the Annexin V-binding buffer. The samples were immediately analyzed by flow cytometry after they were stained with $2 \mu \mathrm{l}$ of FITC-labeled Annexin V and $2 \mu \mathrm{l}$ of PI (BD FACSAria ${ }^{\mathrm{TM}}$ ).

Statistical analysis. Data were analyzed using the computer program SPSS 15.0 (SPSS, Inc.) by means of an unpaired twotailed Student's t-test. Continuous data are expressed as the means \pm SEM. Results were considered statistically significant at a P-value of $<0.05$.

\section{Results}

Low-dose taurine reduces the apoptosis of cardiomyocytes and improves cardiac function. Annexin V and PI assays were conducted in vitro to assess the apoptosis of cardiomyocytes. The early apoptosis of cardiomyocytes was increased within 15 min after the induction of hypoxia (Fig. 1A). In addition, low-dose taurine treatment $(40 \mathrm{mM})$ significantly reduced the apoptosis of cardiomyocytes induced by hypoxia, whereas highdose taurine treatment $(120 \mathrm{mM})$ was not effective (Fig. 1B).

As shown by H\&E staining, the cardiomyocytes in the ischemic myocardial tissues $2 \mathrm{~h}$ after AMI were stretched and narrow in shape, and the gaps between these cardiomyocytes were wider in vivo when compared with the control group $2 \mathrm{~h}$ after modeling. The gaps between the cardiomyocytes were narrower when the AMI rats were treated with taurine $(100 \mathrm{mg} / \mathrm{kg} / \mathrm{day})$ (Fig. 1C). Furthermore, TUNEL staining indicated that there were more apoptotic cardiomyocytes $2 \mathrm{~h}$ after modeling in the ischemic cardiac tissues than in the control ones. Moreover, the administration of taurine inhibited the apoptosis of the cardiomyocytes (Fig. 1D). We also 
A Taurine content in cardiocytes after hypoxia

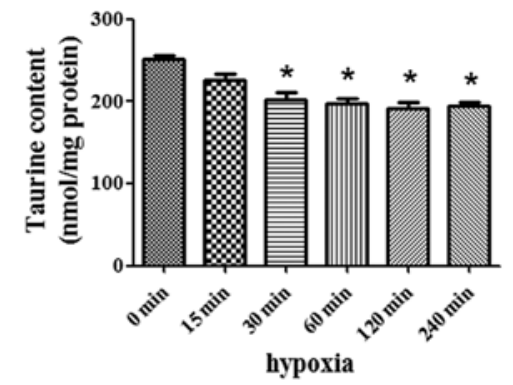

B

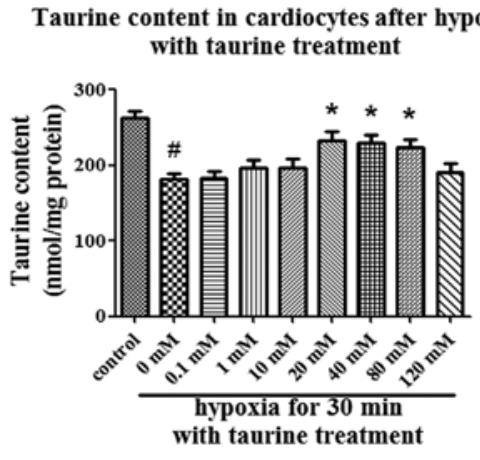

C Taurine content in cardiac tissue $0.5 \mathrm{~h}$ after modeling

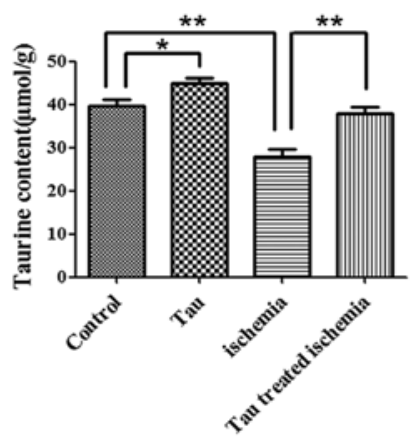

Taurine content in cardiac tissue $2 \mathrm{~h}$ after modeling

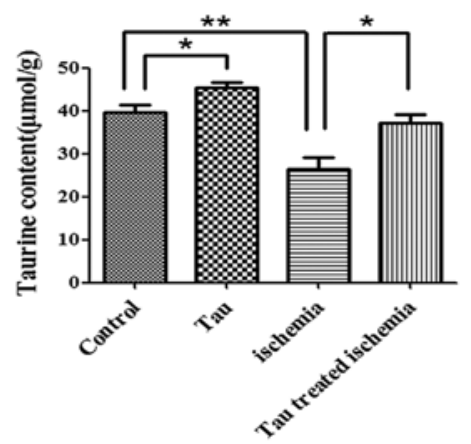

D Taurine content in plasma $0.5 \mathrm{~h}$ after modeling

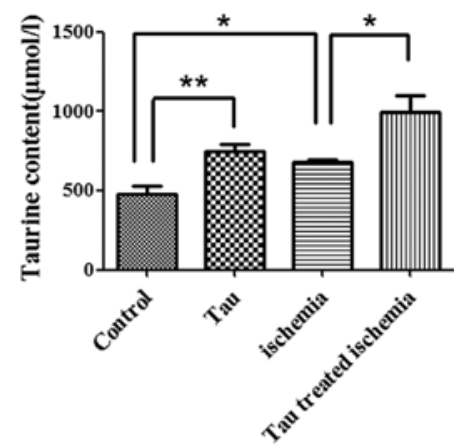

Taurine content in plasma $2 \mathrm{~h}$ after modeling

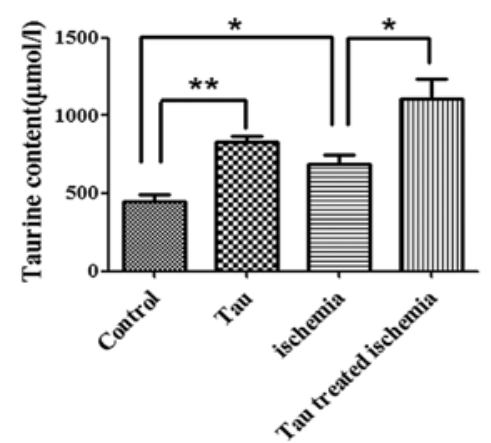

Figure 2. Taurine contents measured by high-performance liquid chromatography. (A) Taurine content in cardiomyocytes exposed to hypoxia. (B) Taurine content in cardiomyocytes exposed to hypoxia with various doses of taurine treatment. (C) Taurine content in ischemic cardiac tissues 30 min and $2 \mathrm{~h}$ after modeling. (D) Taurine content in plasma in rats with acute myocardial ischemia $30 \mathrm{~min}$ and $2 \mathrm{~h}$ after modeling. Columns represent the means of 6 samples in each group; bars represent the means $\pm \mathrm{SEM} ;{ }^{*} \mathrm{P}<0.05 ;{ }^{* *} \mathrm{P}<0.01$. Tau, taurine.

Table I. Clinical characteristics of the patients.

\begin{tabular}{lccc}
\hline Characteristic & AMI & Control & P-value \\
\hline Age (years) & $68 \pm 7.5$ & $58 \pm 14.5$ & $>0.05$ \\
Male/female & $10 / 0$ & $8 / 2$ & $>0.05$ \\
Hypertension (\%) & $60 \%$ & $40 \%$ & $>0.05$ \\
Diabetes $(\%)$ & $40 \%$ & $20 \%$ & $>0.05$ \\
Cholesterol $(\mathrm{mmol} / \mathrm{l})$ & $4.17 \pm 0.17$ & $3.64 \pm 0.21$ & $>0.05$ \\
Triglyceride $(\mathrm{mmol} / \mathrm{l})$ & $1.85 \pm 0.36$ & $1.53 \pm 0.33$ & $>0.05$
\end{tabular}

Taurine content

in plasma $(\mu \mathrm{mol} / \mathrm{l}) \quad 493.7 \pm 51.94 \quad 358.5 \pm 12.59$

0.029

AMI, acute myocardial ischemia.

detected the anti-apoptotic gene, $\mathrm{Bcl}-2$, and the pro-apoptotic gene, Bax, in the cardiac tissues by western blot analysis. Our data showed that the expression of Bcl-2 was significantly decreased $2 \mathrm{~h}$ after modeling in the AMI group as compared with the control group, and that the supplementation of exogenous taurine significantly elevated the levels of Bcl-2. On the contrary, the expression of Bax was increased in the AMI group, which was reversed by taurine treatment (Fig. 1E).

Echocardiogram examinations were performed 2 weeks after modeling. Cardiac function was determined by the left ventricular diastolic and systolic internal dimensions (LVIDd and LVIDs, respectively), the percentage of fractional shortening
(FS) and the ejection fraction (EF). The LVIDd and LVIDs were significantly increased in the AMI group, and were reduced following taurine treatment. Accordingly, the FS and EF were significantly decreased in the AMI group, and this decrease was also reversed following taurine treatment (Fig. 1F).

Low-dose taurine increases the intracellular taurine content which decreases under hypoxic and ischemic stress conditions. The taurine content in the cardiomyocytes was $202.5 \pm 8.2 \mathrm{nmol} / \mathrm{mg}$ protein when the cells were cultured under hypoxic conditions for $30 \mathrm{~min}$, which was significantly decreased as compared with the cells cultured under normoxic conditions $(251.3 \pm 5.2 \mathrm{nmol} / \mathrm{mg}$ protein, $\mathrm{P}<0.01)$ (Fig. $2 \mathrm{~A}$ ). In contrast to high-dose taurine (120 nM), low-dose taurine $(40 \mathrm{mM})$ elevated the intracellular taurine content, which was decreased under hypoxic conditions (Fig. 2B).

In rats with AMI, the taurine content in the ischemic areas of the cardiac tissues $30 \mathrm{~min}$ and $2 \mathrm{~h}$ after modeling was $27.99 \pm 1.66$ and $26.54 \pm 2.57 \mu \mathrm{mol} / \mathrm{g}$, respectively. These levels were significantly lower than those of the control group at $30 \mathrm{~min}(39.57 \pm 1.56 \mu \mathrm{mol} / \mathrm{g})$ and at $2 \mathrm{~h}(39.71 \pm 1.63 \mu \mathrm{mol} / \mathrm{g})$ after modeling $(\mathrm{P}<0.05)$ (Fig. $2 \mathrm{C})$. On the contrary, the plasma taurine content in the rats with AMI was increased as compared with that in the rats of the control group at $30 \mathrm{~min}$ $(680.0 \pm 15.67$ vs. $480.6 \pm 52.14 \mu \mathrm{mol} / \mathrm{l})$ and at $2 \mathrm{~h}(685.1 \pm 63.56$ vs. $448.7 \pm 41.47 \mu \mathrm{mol} / \mathrm{l})$ after modeling $(\mathrm{P}<0.05)$ (Fig. 2D). This was in accordance with the change in plasma taurine content in AMI patients which was increased compared with the control group (493.7 \pm 51.94 vs. $358.5 \pm 12.59 \mu \mathrm{mol} / 1, \mathrm{P}<0.05$ ) (Table I). 

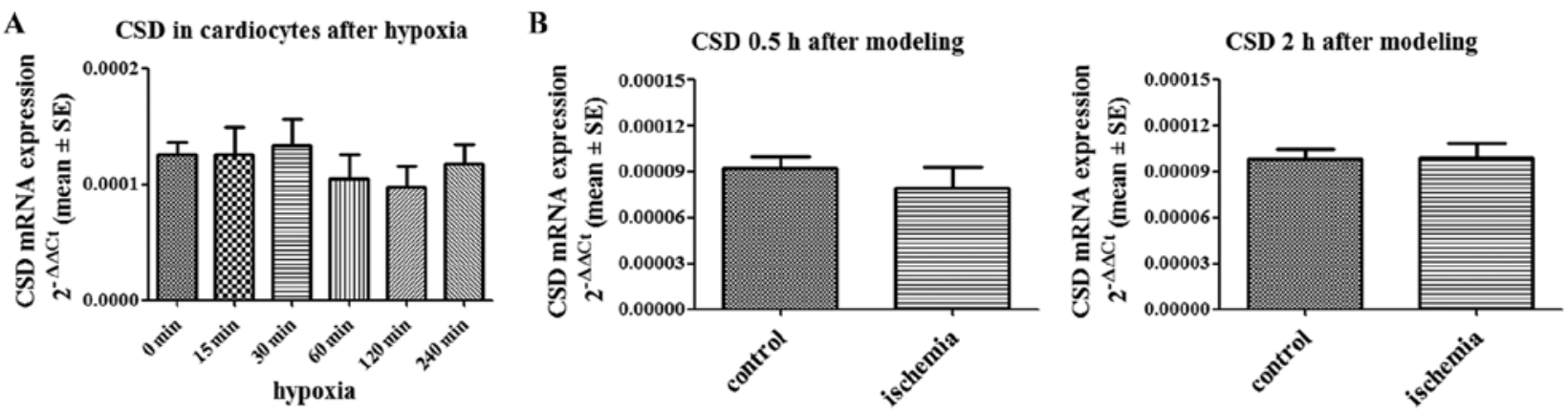

Figure 3. Cysteine sulfinate decarboxylase (CSD) expression in cardiomyocytes and cardiac tissues. (A) Levels of CSD mRNA expression in hypoxic cardiomyocytes. (B) Levels of CSD mRNA expression in ischemic cardiac tissues $30 \mathrm{~min}$ and $2 \mathrm{~h}$ after modeling as measured by quantitative PCR. Columns represent the means of 6 samples in each group; bars represent the means \pm SEM.

When the AMI rats were treated with taurine, the taurine content in the cardiac tissues content was elevated to $37.99 \pm 1.49$ and $37.13 \pm 2.08 \mu \mathrm{mol} / \mathrm{g}$ at $30 \mathrm{~min}$ and at $2 \mathrm{~h}$ after modeling, respectively; these levels were significantly higher than those in the AMI group not treated with taurine $(\mathrm{P}<0.05)$ (Fig. 2C). Finally, the taurine content in the plasma was increased following taurine treatment in the control and AMI rats due to the supplementation of exogenous taurine (Fig. 2D).

CSD expression levels are not altered in hypoxic cardiomyocytes and ischemic cardiac tissues. CSD, which is involved in biosynthesis pathways, is the rate-limiting enzyme in taurine biosynthesis $(16,17)$. We quantified the expression of CSD mRNA in hypoxic cardiomyocytes and ischemic cardiac tissues. No difference was found between hypoxic cardiomyocytes and normoxic cardiomyocytes (Fig. 3A). CSD expression was also not altered in the ischemic areas of the cardiac tissue from the rats with AMI compared with the controls (Fig. 3B).

Low-dose taurine upregulates TAUT expression, which is downregulated by hypoxia and AMI. Real-time quantitative reverse transcription PCR revealed that the expression of TAUT mRNA in the cardiomyocytes was downregulated at 30 min under hypoxic conditions. Western blot analysis and immunofluorescence demonstrated that the protein expression of TAUT was also downregulated $30 \mathrm{~min}$ after hypoxia, which paralleled the changes in TAUT mRNA expression (Fig. 4A). Furthermore, low-dose taurine $(40 \mathrm{mM})$ significantly upregulated TAUT mRNA expression, which had been downregulated by hypoxia. However, high-dose taurine $(120 \mathrm{mM})$ had no effect on the expression of TAUT mRNA. Western blot analysis and immunofluorescence also confirmed that the protein levels of TAUT were in accordance with the mRNA levels (Fig. 4B and D). Our results also demonstrated that low-dose taurine upregulated the mRNA and protein levels of TAUT in the normoxic cardiomyocytes (Fig. 4C and D).

As compared with the control group, the mRNA expression of TAUT in the cardiac tissues in the AMI group was reduced by $78 \%$ at $30 \mathrm{~min}$ after modeling and by $82 \%$ at $2 \mathrm{~h}$ after modeling (Fig. 4E). In addition, the protein levels of TAUT in the cardiac tissues obtained $2 \mathrm{~h}$ after modeling measured by western blot analysis and immunohistochemistry were in accordance with the changes in the mRNA levels described above (Fig. 4F and G). As compared with the AMI rats not treated with taurine, those treated with low-dose taurine had mRNA levels of TAUT in cardiac tissues that were elevated by 3.1 -fold at $30 \mathrm{~min}$ after modeling and by 2.7 -fold at $2 \mathrm{~h}$ after modeling. (Fig. 4E). Moreover, the protein levels of TAUT were also reversed by taurine treatment (Fig. 4F and G).

\section{Discussion}

Coronary heart disease is the most common cause of mortality worldwide (18), and AMI can lead to serious consequences such as arrhythmia and heart failure. There are many preventative and therapeutic interventions for coronary heart disease, such as statin therapy, anticoagulants and percutaneous coronary intervention.

Populations with higher fish consumption have lower cardiovascular death rates than populations with high meat consumption (19), which may be associated with high taurine concentrations in fish (20). Taurine is abundant in cardiac tissue and exerts protective effects on many tissues and cells (particularly cardiomyocytes) by its osmoregulatory, anti-oxidative, $\mathrm{Ca}^{2+}$-modulating, and plasma membrane-stabilizing effects (1). In addition, taurine effectively prevents myocardial ischemiainduced apoptosis by inhibiting the assembly of the Apaf-1/ caspase-9 apoptosome and the Akt/caspase-9 pathway $(9,10)$. Taurine prevents arsenic-induced myocardial pathophysiology by attenuating $\mathrm{NF}-\kappa \mathrm{B}$ activation via IKK, p38 and the JNK MAPK signaling pathways (21). In addition, taurine prevents the apoptosis of cardiomyocytes by inhibiting NADPH oxidase and calpain activation (22).

Endogenous taurine is synthesized from methionine and cysteine, which are its amino acid precursors. CSD is considered as the key rate-limiting enzyme in the biosynthesis of taurine (23). Mammalian species such as humans and rats are unable to synthesize sufficient taurine and must rely on dietary sources to maintain their requirements. Moreover, intracellular concentrations of taurine are much higher than extracellular concentrations (24). TAUT, which is a high-affinity and lowcapacity sodium- and chloride-dependent transporter located on the cell membrane, maintains this transmembrane gradient. The expression of TAUT is downregulated by high concentrations of glucose, the p53 tumor suppressor protein, endothelin and certain diseases, such as hypertension. On the contrary, hypertonicity, tumor necrosis factor- $\alpha$ and nitric oxide upregulate the expression of TAUT (25). 
A
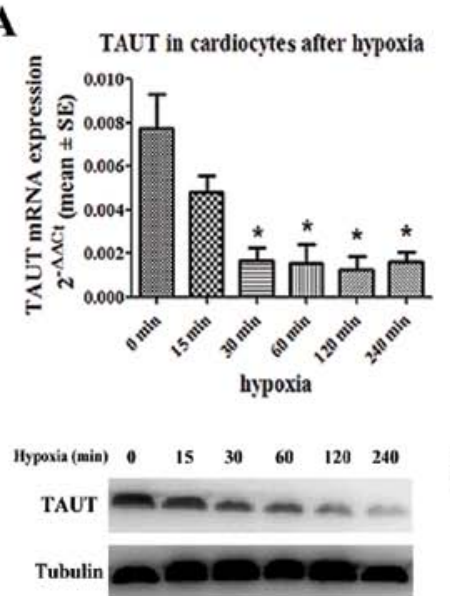

D

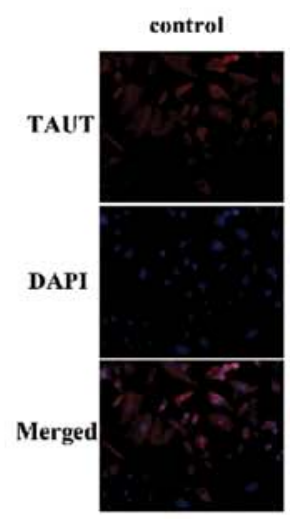

$\mathbf{E}$
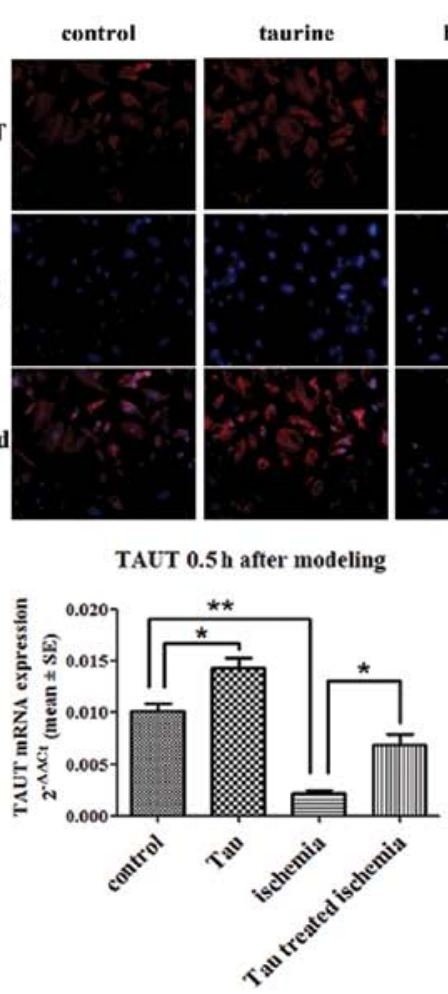

B

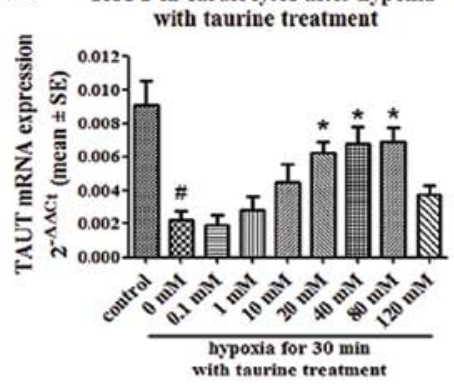

Hypoxia 30 min - + + + + + + +

$\begin{array}{llllllllll}\text { Taurine }(\mathrm{mM}) & 0 & 0 & 0.1 & 1 & 10 & 20 & 40 & 80 & 120\end{array}$

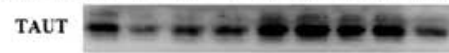

Tubulin
C
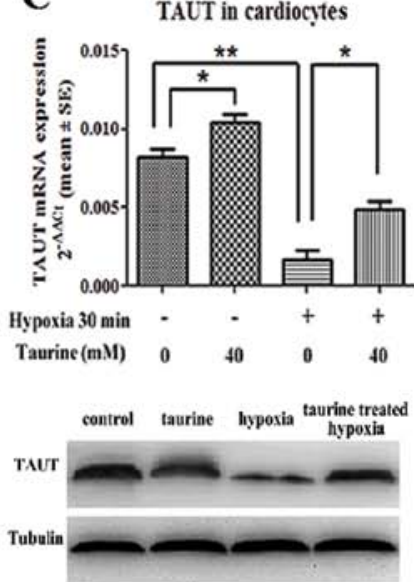

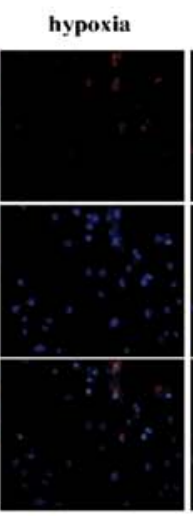

taurine $40 \mathrm{mM}$ taurine $120 \mathrm{mM}$ treated hypoxia treated hypoxia
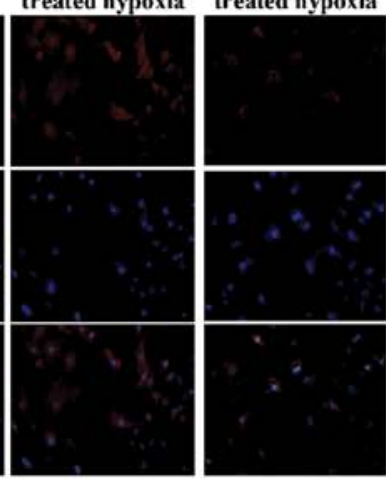

TAUT $2 \mathrm{~h}$ after modeling

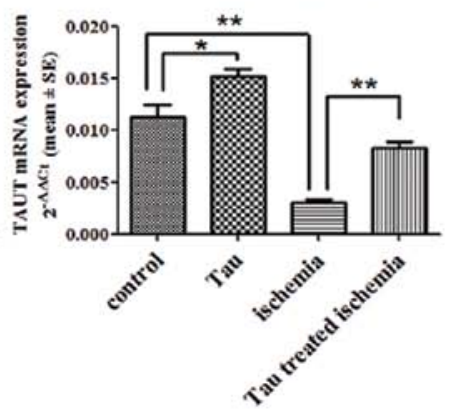

F

G
를

control

Taurine
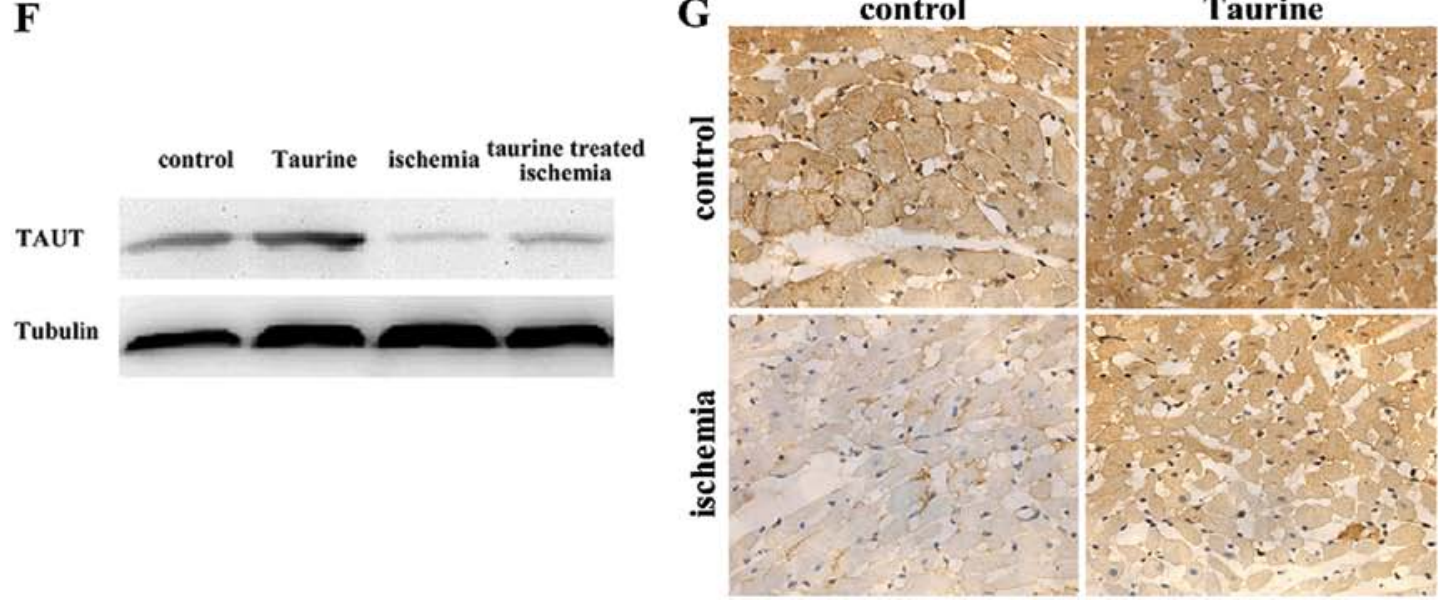

Figure 4. TAUT expression in cardiomyocytes and cardiac tissues. (A) mRNA and protein levels of TAUT in hypoxic cardiomyocytes measured by PCR as shown by western blot analysis. (B) mRNA and protein levels of TAUT in hypoxic cardiomyocytes with taurine treatment. (C) mRNA and protein levels of TAUT expression in cardiomyocytes exposed to hypoxia with low-dose taurine treatment. (D) Protein levels of TAUT in hypoxic cardiomyocytes with taurine treatment measured by immunofluorescence analysis. (E) mRNA levels of TAUT in cardiac tissues 30 min and $2 \mathrm{~h}$ after modeling as measured by quantitative PCR. Tau, taurine. (F and G) Protein levels of TAUT $2 \mathrm{~h}$ after modeling as measured by western blot analysis and immunohistochemistry analysis. Original magnification, $\mathrm{x} 200$; Columns represent the means of 6 samples in each group; bars represent the means $\pm \mathrm{SEM} ;{ }^{*} \mathrm{P}<0.05 ;{ }^{* *} \mathrm{P}<0.01$. 
The present study confirmed that taurine treatment inhibited the apoptosis of cardiomyocytes. The echocardiogram examination showed that the EF and FS values which were significantly decreased in the rats with AMI, were reversed following taurine treatment. The apoptosis of cardiomyocytes which increased under hypoxic and ischemic conditions was also inhibited following taurine treatment. Multiple studies have revealed the protective effects of taurine on cardiomyocytes (4-6,9). However, changes in intracellular taurine content and the expression of TAUT in cardiomyocytes have not been previously clarified following taurine treatment.

A previous study demonstrated that the taurine content in the myocardium and aortic wall in spontaneously hypertensive rats was decreased, which may be a result of the decreased TAUT activity and affinity, and the downregulation of TAUT gene expression (26). Our study demonstrated that taurine concentrations in hypoxic cardiomyocytes and ischemic cardiac tissues were reduced as compared with the controls. Inversely, the taurine concentrations in plasma were higher in the rats with AMI than in the control rats, which was confirmed in AMI patients. Although the expression of CSD mRNA was similar in the hypoxic and normal cardiomyocytes and in the cardiac tissues of rats with or without AMI, the mRNA and protein expression of TAUT in the hypoxic cardiomyocytes and ischemic myocardial tissues was decreased as compared with the controls. As CSD is the key rate-limiting enzyme in the biosynthesis of taurine, these results suggest that the biosynthesis of taurine was not altered in the hypoxic cardiomyocytes and ischemic cardiac tissues. The reason why taurine concentrations were decreased in hypoxic cardiomyocytes and ischemic cardiac tissues and increased in the plasma of AMI rats appears secondary to the reduced expression of TAUT, ultimately causing dysfunctional taurine transport. The downregulation of TAUT expression and decreased concentrations of taurine occurred $30 \mathrm{~min}$ after modeling, which indicates that the concentration of taurine may be an early marker for AMI. This is significant, as the early diagnosis of AMI can lead to early interventional therapies. Cardiac troponin $\mathrm{T}$ is a classical and useful marker of AMI; however, it is generally upregulated 2 or $3 \mathrm{~h}$ after ischemia. Consequently, the concentration of taurine captures our attention since it changes within $<30$ min following the induction of ischemia. Of note, the concentration of taurine can be detected by a non-invasive examination termed nuclear magnetic resonance spectroscopy (NMRS) in the hippocampal formation of rats (27). Further studies are required to detect the taurine content in ischemic cardiac tissues by NMRS.

Taurine supplementation may prevent cardiomyocytes from undergoing apoptosis. Our results revealed that treatment with low-dose $(40 \mathrm{mM})$ but not high-dose $(120 \mathrm{mM})$ taurine increased the expression of TAUT and the taurine content in hypoxic cardiomyocytes. Previous studies have demonstrated that extracellular taurine can regulate the expression of TAUT in many other cell types. For instance, it has been reported that low-dose taurine treatment $(0.1,1$ and $10 \mathrm{mM})$ reverses diabetes-induced or high glucose-induced decreases in TAUT expression in retinal glial cells (28). Additionally, TAUT expression has been shown to be downregulated in HepG2 human hepatoblastoma cells following treatment with $50 \mathrm{mM}$ of extracellular taurine (29). Various doses of taurine may also have different effects. For example, it has been shown in rat myocardial mitochondria that low-dose taurine (5 and $10 \mathrm{mM})$ increases $\mathrm{Ca}^{2+}$-ATPase activity, whereas high-dose taurine (20 mM) inhibits $\mathrm{Ca}^{2+}$-ATPase activity (30). Our in vitro study demonstrated that low-dose taurine upregulated TAUT expression and increased the intracellular content of taurine, but that high-dose taurine had no effect. In our study, in vivo taurine supplementation by intraperitoneal injection increased the expression of TAUT in cardiac tissues in normal rats as well as in rats with AMI. As a result, the concentration of taurine in cardiac tissue was also elevated in both taurine-treated normal rats and taurine-treated AMI rats. The dose of taurine (100 mg/kg/day) used for our in vivo study may be considered a low-dose according to a previous study (31). In fact, we did not administer high-dose taurine in vivo since in clinical practice, lower drug doses are preferable. These results suggest that the upregulation of TAUT expression by taurine supplementation occurs through a positive feedback pathway. The elevated intra-cardiocyte taurine content and the upregulation of TAUT expression were protective factors for the cardiomyocytes under ischemic conditions. Taurine therapy, even at a low-dose, is a reliable interventional modality to protect cardiomyocytes in rats with AMI.

In conclusion, taurine exerts a protective effect on the ischemic myocardium. Low-dose but not high-dose taurine upregulates TAUT expression and increases the intra-cardiocyte taurine content in hypoxic cardiomyocytes and ischemic myocardial tissues. Further studies are required to evaluate the mechanism behind TAUT dysfunction in cardiovascular disease and to investigate the clinical applications of taurine as a therapeutic agent in AMI.

\section{Acknowledgements}

This study was supported by a grant from the National Basic Research Program of China (no. 2011CB503905).

\section{References}

1. Huxtable RJ: Physiological actions of taurine. Physiol Rev 72: 101-163, 1992.

2. Chapman RA, Suleiman MS and Earm YE: Taurine and the heart. Cardiovasc Res 27: 358-363, 1993.

3. Azuma J, Hasegawa H, Sawamura A, et al: Therapy of congestive heart failure with orally administered taurine. Clin Ther 5: 398-408, 1983.

4. Azuma J, Sawamura A, Awata N, et al: Therapeutic effect of taurine in congestive heart failure: a double-blind crossover trial. Clin Cardiol 8: 276-282, 1985.

5. Takihara K, Azuma J, Awata N, et al: Beneficial effect of taurine in rabbits with chronic congestive heart failure. Am Heart J 112: 1278-1284, 1986.

6. Oudit GY, Trivieri MG, Khaper N, et al: Taurine supplementation reduces oxidative stress and improves cardiovascular function in an iron-overload murine model. Circulation 109: 1877-1885, 2004.

7. Schaffer S, Takahashi K and Azuma J: Role of osmoregulation in the actions of taurine. Amino Acids 19: 527-546, 2000.

8. Satoh H and Sperelakis N: Review of some actions of taurine on ion channels of cardiac muscle cells and others. Gen Pharmacol 30: 451-463, 1998.

9. Takatani T, Takahashi K, Uozumi Y, et al: Taurine prevents the ischemia-induced apoptosis in cultured neonatal rat cardiomyocytes through Akt/caspase-9 pathway. Biochem Biophys Res Commun 316: 484-489, 2004.

10. Takatani T, Takahashi K, Uozumi Y, et al: Taurine inhibits apoptosis by preventing formation of the Apaf-1/caspase- 9 apoptosome. Am J Physiol Cell Physiol 287: C949-C953, 2004. 
11. Bitoun M, Levillain O and Tappaz M: Gene expression of the taurine transporter and taurine biosynthetic enzymes in rat kidney after antidiuresis and salt loading. Pflugers Arch 442: 87-95, 2001.

12. Han X, Budreau AM and Chesney RW: Adaptive regulation of MDCK cell taurine transporter (pNCT) mRNA: transcription of pNCT gene is regulated by external taurine concentration. Biochim Biophys Acta 1351: 296-304, 1997.

13. Takahashi K, Ohyabu Y, Takahashi K, et al: Taurine renders the cell resistant to ischemia-induced injury in cultured neonatal rat cardiomyocytes. J Cardiovasc Pharmacol 41: 726-733, 2003.

14. Oriyanhan W, Yamazaki K, Miwa S, Takaba K, Ikeda T and Komeda M: Taurine prevents myocardial ischemia/reperfusioninduced oxidative stress and apoptosis in prolonged hypothermic rat heart preservation. Heart Vessels 20: 278-285, 2005.

15. Shi YR, Gao L, Wang SH, et al: Inhibition of taurine transport by high concentration of glucose in cultured rat cardiomyocytes. Metabolism 52: 827-833, 2003.

16. Reymond I, Bitoun M, Levillain O and Tappaz M: Regional expression and histological localization of cysteine sulfinate decarboxylase mRNA in the rat kidney. J Histochem Cytochem 48: 1461-1468, 2000

17. Beetsch JW and Olson JE: Taurine synthesis and cysteine metabolism in cultured rat astrocytes: effects of hyperosmotic exposure. Am J Physiol 274: C866-C874, 1998.

18. World Health Organization: Global Burden of Disease. WHO Press, Geneva, 2008.

19. Mozaffarian D and Rimm EB: Fish intake, contaminants, and human health: evaluating the risks and the benefits. JAMA 296: 1885-1899, 2006.

20. Nittynen L, Nurminen ML, Korpela R and Vapaatalo H: Role of arginine, taurine and homocysteine in cardiovascular diseases. Ann Med 31: 318-326, 1999.

21. Ghosh J, Das J, Manna P and Sil PC: Taurine prevents arsenicinduced cardiac oxidative stress and apoptotic damage: role of NF-kappa B, p38 and JNK MAPK pathway. Toxicol Appl Pharmacol 240: 73-87, 2009.
22. Li Y, Arnold JM, Pampillo M, Babwah AV and Peng T: Taurine prevents cardiomyocyte death by inhibiting NADPH oxidasemediated calpain activation. Free Radic Biol Med 46: 51-61, 2009.

23. Bitoun M and Tappaz M: Gene expression of the transporters and biosynthetic enzymes of the osmolytes in astrocyte primary cultures exposed to hyperosmotic conditions. Glia 32: 165-176, 2000.

24. Ramamoorthy S, Leibach FH, Mahesh VB, et al: Functional characterization and chromosomal localization of a cloned taurine transporter from human placenta. Biochem J 300: 893-900, 1994.

25. Tappaz ML: Taurine biosynthetic enzymes and taurine transporter: molecular identification and regulations. Neurochem Res 29: 83-96, 2004.

26. Shi YR, Qi YF, Bu DF, et al: Dysfunction of myocardial and vascular taurine transport in spontaneously hypertensive rats. Sheng Li Xue Bao 54: 359-364, 2002.

27. Melo TM, Nehlig A and Sonnewald U: Metabolism is normal in astrocytes in chronically epileptic rats: a (13)C NMR study of neuronal-glial interactions in a model of temporal lobe epilepsy. J Cereb Blood Flow Metab 25: 1254-1264, 2005.

28. Zeng K, Xu H, Mi M, et al: Effects of taurine on glial cells apoptosis and taurine transporter expression in retina under diabetic conditions. Neurochem Res 35: 1566-1574, 2010.

29. Satsu H, Terasawa E, Hosokawa Y and Shimizu M: Functional characterization and regulation of the taurine transporter and cysteine dioxygenase in human hepatoblastoma HepG2 cells. Biochem J 375: 441-447, 2003

30. Chang L, Zhao J, Xu J, Jiang W, Tang CS and Qi YF: Effects of taurine and homocysteine on calcium homeostasis and hydrogen peroxide and superoxide anions in rat myocardial mitochondria. Clin Exp Pharmacol Physiol 31: 237-243, 2004.

31. Sahin MA, Yucel O, Guler A, et al: Is there any cardioprotective role of Taurine during cold ischemic period following global myocardial ischemia? J Cardiothorac Surg 6: 31, 2011. 